\title{
PSA-based prostate cancer screening: the role of active surveillance and informed and shared decision making
}

\author{
Lionne D F Venderbos and Monique J Roobol
}

Since the first publication describing the identification of prostate-specific antigen (PSA) in the 1960 s, much progress has been made. The PSA test changed from being initially a monitoring tool to being also used as a diagnostic tool. Over time, the test has been heavily debated due to its lack of sensitivity and specificity. However, up to now the PSA test is still the only biomarker for the detection and monitoring of prostate cancer. PSA-based screening for prostate cancer is associated with a high proportion of unnecessary testing and overdiagnosis with subsequent overtreatment. In the early years of screening for prostate cancer, high rates of uptake were very important. However, over time the opinion on PSA-based screening has shifted towards the notion of informed choice. Nowadays, it is thought to be unethical to screen men without them being aware of the pros and cons of PSA testing, as well as the fact that an informed choice is related to better patient outcomes. Now, as the results of three major screening studies have been presented and the downsides of screening are becoming better understood, informed choice is becoming more relevant.

Asian Journal of Andrology (2011) 13,219-224; doi:10.1038/aja.2010.180; published online 7 February 2011

Keywords: active surveillance; informed decision making; PSA testing; shared decision making

\section{INTRODUCTION}

The incidence of prostate cancer (PC) is rising in most Eastern and Western countries. In Europe the disease affects approximately 225000 men each year. ${ }^{1}$ The increase can be explained by the increasing overall life expectancy of men, the increasing number of biopsies and cores per biopsy, and most importantly, the increasing use of prostate-specific antigen (PSA) measurements as a screening test. ${ }^{2}$

The first publication describing PSA appeared in $1960 .^{3}$ Difference of opinion exists as to who should be credited for its discovery, as different groups isolated the same protein simultaneously. ${ }^{4}$ In 1986, the American Food and Drug Association approved the PSA as a test to aid in the management of patients diagnosed with PC. In 1994, the PSA test was approved by the American Food and Drug Association as a diagnostic tool which can be used, for instance, for the early detection of PC. ${ }^{4}$ Throughout the years, it became clear that the use of the PSA test in a screening setting has both advantages and disadvantages. The published results of the European Randomized study of Screening for Prostate Cancer (ERSPC), ${ }^{5}$ the Prostate, Lung, Colorectal, and Ovarian Cancer Screening Trial, ${ }^{6}$ and the Gothenburg randomized population-based PC screening trial, ${ }^{7}$ all initiated in the early 1990 s, provide evidence on whether PSA testing is beneficial. The data from the three studies point towards a disease-specific mortality reduction due to screening, as well as the fact that screening by using a PSA test leads to overdiagnosis and therefore overtreatment. ${ }^{5-7}$ The apparent controversial outcomes - with on the one hand a mortality reduction and on the other hand overdiagnosis and overtreatment-have motivated some professionals (i.e. primary care providers and/or urologists) to strongly recommend against PSA testing and some to strongly advise in favor of testing. Very few professionals truly inform men about the pros and cons of the PSA test. ${ }^{8}$ Because more specific biomarkers are still lacking, the most commonly used screening test remains the serum PSA test. Disadvantages of the PSA test are the false-positive and false-negative results. A false-negative result can create uncertainty, while false-positive tests may lead to unnecessary additional testing. ${ }^{9,10}$ At the same time, men feel pressured or even encouraged by family members, friends or media to consider PSA testing. ${ }^{8,11,12}$ In the light of the confusing situation that has occurred, informed decision making about whether a men should or should not get tested seems more needed than ever.

\section{INCIDENCE AND MORTALITY OF PC}

Different incidence and mortality rates for PC are found around the world (Table 1). It appears that Asia has the lowest incidence and mortality rates, while the highest rates are nowadays found in the United States. ${ }^{13}$ After the introduction of the PSA test, the incidence of PC increased drastically. Recent data from the US Surveillance, Epidemiology and End Results program confirm this; new cases of PC have increased substantially in 1975-2005. The introduction of the PSA test led to a steep increase in PC incidence. Over time incidence declined; however, incidence rates did not retain to the level that was seen before the introduction of the PSA test. If this would reflect a true increase of the disease, it should be accompanied by an increase in disease-specific death rates, which is not the case. In fact, the mortality rates for PC declined during this period. ${ }^{14}$ As the increase in incidence and mortality rates does not appear simultaneously, another explanation has to be found. According to Murphy et al., ${ }^{15}$ the trend can be 
Table 1 Age-standardized incidence (world standard population) and mortality rates for prostate cancer in Asia, Europe and America, 2002 estimates $^{a}$

\begin{tabular}{|c|c|c|}
\hline World region & Incidence per 100000 & Mortality per 100000 \\
\hline Eastern Asia & 3.8 & 1.9 \\
\hline South Central Asia & 4.4 & 2.8 \\
\hline South-Eastern Asia & 7 & 4.5 \\
\hline Western Asia & 10.9 & 6 \\
\hline Eastern Europe & 17.3 & 9.7 \\
\hline Southern Europe & 35.5 & 13.2 \\
\hline Northern Europe & 57.4 & 19.7 \\
\hline Western Europe & 61.6 & 17.5 \\
\hline Central America & 30.6 & 15.5 \\
\hline South America & 47 & 18 \\
\hline Northern America & 119.9 & 15.8 \\
\hline
\end{tabular}

${ }^{a}$ Data source: Globocan - Cancer incidence, mortality and prevalence worldwide, 2002. ${ }^{13}$

explained by the large stage shift from palpable and locally advanced disease to impalpable and localized disease. Due to PSA-based screening for PC, increasing numbers of patients with low-risk tumors (with low risk for both metastasis and mortality) are being detected. ${ }^{1}$ These potentially clinically insignificant PCs (PSA $<10 \mathrm{ng} \mathrm{ml}^{-1}$, stage $\leqslant \mathrm{T} 2 \mathrm{a}$ disease and Gleason $\leqslant 6)^{16,17}$ would not have been diagnosed without screening and may not lead to symptoms or death during the patient's lifetime. Within the screening arm of the ERSPC (section Rotterdam, the Netherlands), $27-56 \%$ of all cancers detected in men aged 55-75 years can be classified as potentially overdiagnosed. ${ }^{18}$

\section{OVERTREATMENT}

The ERSPC reported in March 2009 that PSA-based screening reduced the rate of death from PC by $20 \%$ in the intention to screen analysis. However, this mortality reduction was associated with a high risk of overdiagnosis and overtreatment. ${ }^{5}$ Overtreatment means that men with overdiagnosed tumors, which would not have caused any symptoms during a man's lifetime if they had remained undiagnosed, are subject to unnecessary costly and invasive treatment. ${ }^{2}$ Despite their indolent character, these low-risk tumors are often actively treated, resulting in so-called overtreatment. ${ }^{19}$ Within the first round of the ERSPC (section Rotterdam), e.g. 293 out of 1014 men with detected PC could be classified as potentially overdiagnosed or 'indolent' and were eligible for active surveillance (AS). It turned out that in only 64 out of the 293 men an initial AS strategy was chosen. ${ }^{20}$ The question thus arises how to deal with overdiagnosis and overtreatment more effectively. A specific biomarker for potentially life-threatening disease would probably solve a large part of the problem; however, no such biomarker is currently available. It is claimed that AS provides a realistic strategy to avoid overtreatment by surgery or radiation therapy. AS starts with a selection process in which men with favorable diseasespecific prognoses are included. The age of a patient and his estimated life expectancy play an important role. Radical treatment is withheld and replaced by closely monitoring the disease. ${ }^{21}$ If progression occurs, curative treatment is indicated. The criteria for switching from AS to delayed curative treatment are based on both medical and nonmedical aspects. A benefit of AS can be the delay of active treatment, including avoidance of possible side effects and the delay of complications for a few years. ${ }^{22}$ However, the psychological aspects of AS should not be ignored during the period of close monitoring. These include the anxiety of being too late for curative treatment.

\section{ACTIVE SURVEILLANCE}

AS is subject of ongoing studies since the 1990s. Klotz et al. ${ }^{23}$ Carter et $a l^{24,25}$ and Kakehi et al. ${ }^{26}$ have all initiated studies regarding the value of AS (Table 2). Klotz et al. ${ }^{23}$ reported on the long-term clinical results of a large, AS cohort with localized PC at the beginning of this year. The cohort consisted of 450 patients with a median age of 70.3 years and a median follow-up of 6.8 years. Klotz et al. ${ }^{23}$ reported that among the 450 patients, 97 patients died (21.6\%) and 353 were alive (78.4\%). The 10 -year overall survival was $68 \%$ (95\% CI, $62-74 \%)$. There was no difference in overall survival between the patients who remained on surveillance and those who were reclassified and treated radically. The reported 5- and 10-year cancer-specific survival rates were 99.7 and $97.2 \%$ for AS and active treatment respectively. In the study period, five PC-related mortalities occurred; all in men who had been reclassified as higher risk and who were offered radical treatment. Radical intervention was undertaken in three of the five patients (radiation $n=2$; prostatectomy $n=1$ ). The other two patients refused treatment. Klotz et al. ${ }^{23}$ conclude that after a mean follow-up of 6.8 years only a single patient died after a relatively prolonged period of observation ( $>2$ years) and subsequently experienced progression. Main reasons for discontinuing AS involve: short PSA doubling time (65/135, 14\% of men of the total cohort) and grade progression (36/135, $8 \%$ of men of the total cohort). Carter et al. ${ }^{25}$ reported in 2007 that out of the 407 men included in the program on expectant management (i.e. the careful selection and monitoring of older men considered to have low-risk disease with the intention to cure if the disease progresses ${ }^{25}$ ), $239(59 \%)$ men remained on AS at a median follow-up of 3.4 years (0.43-12.5). A total of 103 (25\%) men underwent curative intervention at a median of 2.2 years after diagnosis (0.96-7.39), 45 (11\%) men withdraw from the program, $12(2 \%)$ men were lost to follow-up and 8 (3\%) men died of causes other than PC. Reasons for withdrawal of the 45 men are not mentioned. Regarding the men who underwent curative intervention, older age at diagnosis $(P=0.011)$ as well as an earlier date of diagnosis $(P=0.001)$ was significantly associated with curative intervention. It should be noted that the John Hopkins approach for selecting and monitoring men differs from that reported by Klotz et al., ${ }^{23}$ and can be considered to be more conservative, i.e. a smaller amount of T2 cancers are included in the John Hopkins pro-

\section{Table 2 Criteria for active surveillance}

\begin{tabular}{|c|c|}
\hline Study & Criteria for active surveillance \\
\hline Klotz et al. ${ }^{23}$ & $\begin{array}{l}\text { 1. Gleason } \leqslant 6 \\
\text { 2. PSA } \leqslant 10 \mathrm{ng} \mathrm{ml}-1 \\
\text { 3. Stage } \mathrm{T} 1 \mathrm{~b} \text { to } \mathrm{T} 2 \mathrm{~b} \text { NOMO } \\
\text { 4. Patients older than } 70 \text { years with } P S A \leqslant 15 \mathrm{ng} \mathrm{ml}^{-1} \text { or Gleason } \\
\leqslant 3+4\end{array}$ \\
\hline Carter et al. ${ }^{24,25}$ & $\begin{array}{l}\text { 1. PSAD } \leqslant 0.15 \mathrm{ng} \mathrm{ml}^{-1} \mathrm{~cm}^{-3} \\
\text { 2. Stage } \mathrm{T} 1 \mathrm{c} \\
\text { 3. Favorable biopsy characteristics, i.e. Gleason } \leqslant 6 \text { with no Gleason } \\
\text { pattern grade of } 4 \text { or } 5 \text {, no more than } 2 \text { cores positive for cancer, } \\
\text { and no more than } 50 \% \text { of any } 1 \text { core involved with cancer }\end{array}$ \\
\hline Kakehi et al. ${ }^{26}$ & $\begin{array}{l}\text { 1. Age ranging between } 50 \text { and } 80 \\
\text { 2. Initial serum PSA of } \leqslant 20 \mathrm{ng} \mathrm{ml} \\
\text { 3. Number of positive core being one or two per } 6-12 \text { systematic } \\
\text { biopsy cores } \\
\text { 4. Gleason score } \leqslant 6 \\
5 \text {. } \leqslant 50 \% \text { cancer involvement in any of the positive cores }\end{array}$ \\
\hline
\end{tabular}

Abbreviations: PSA, prostate-specific antigen, PSAD, prostate-specific antigen density.

a PSAD: PSA before diagnosis divided by prostate volume determined by transrectal ultrasound measurement. 
gram. Kakehi et al. ${ }^{26}$ reported the first prospective study on AS in Japanese patients where PC was detected using only a PSA elevation. The study included 134 men; of whom 118 chose the AS program and 16 chose immediate curative treatment at enrolment. Up to 31 October 2006, no manifestation of metastasis or cancer death was observed in any of the participants. Three men died due to other disease, while five men were lost to follow-up. ${ }^{26}$ Of the 118 patients who chose AS as initial treatment, 54 (46\%) remained on AS for the maximal observation period of 54 months. Reasons for discontinuing AS were: a PSA doubling time $\leqslant 2$ years (17/65), pathology progression $(16 / 65)$, change in T-stage (1/65), patient's preference $(15 / 65)$ and comorbidities $(8 / 65)$. For seven men who discontinued AS, reasons are unknown. Kakehi et al. ${ }^{26}$ reported that during the observation period, no serious adverse events were observed: not in the AS program group and not in those men who chose immediate treatment.

\section{PROSTATE CANCER RESEARCH INTERNATIONAL: ACTIVE SURVEILLANCE (PRIAS) STUDY}

Within the ERSPC (section Rotterdam), the prospective, observational PRIAS study has been initiated as a decision aid for the urologists managing their patients with AS and at the same time with the aim of validating this management. ${ }^{2}$ It is an entirely web-based study. Potential patients can retrieve study information from the website (www.prias-project.org). Inclusion and follow-up data of patients can be entered in on the website after an urologist has gained access to the secured parts of the web tool. When data of a follow-up visit are entered, the website presents a graph survey of the PSA measurements and the PSA doubling time. On the basis of the follow-up criteria, a recommendation will be presented to the urologist on whether the patient should continue on AS or whether to discontinue and opt for active treatment. So, besides being a helpful tool for urologists in daily clinical practice, the website supports in clinical practice by providing decision points during AS.

By defining inclusion and follow-up criteria (Table 3), the PRIAS study is attempting to select men with insignificant organ-confined tumors who have a favorable prognosis. Other arguments in choosing AS include age, quality of life issues, ethical aspects and costs associated with treatment. ${ }^{27}$ Currently, the PRIAS study is applied in several medical centers across the Netherlands, as well as in other European countries, the United States, Canada, Japan and Australia. The initiators and participating centers of the PRIAS study hope to provide a

Table 3 Inclusion and follow-up criteria for the PRIAS study ${ }^{19}$

\section{Criteria}

\begin{tabular}{|c|c|}
\hline Inclusion & $\begin{array}{l}\text { 1. Men should: } \\
\text { - have histologically proven adenocarcinoma of the prostate } \\
\text { - be fit for curative treatment } \\
\text { - be willing to attend the follow-up visits } \\
\text { - not have received former therapy for prostate cancer } \\
\text { 2. Clinical stage is T1C or T2 } \\
\text { 3. Gleason score is } \leqslant 6 \text { and } \leqslant 2 \text { biopsy cores are invaded with prostate } \\
\text { cancer } \\
\text { 4. PSA } \leqslant 10 \mathrm{ng} \mathrm{ml}^{-1} \text { and PSA density } \leqslant 0.2 \mathrm{ng} \mathrm{ml}^{-1} \mathrm{~cm}^{-3}\end{array}$ \\
\hline Follow-up & $\begin{array}{l}\text { 1. The patient is content with active surveillance } \\
\text { 2. Clinical stage remains }<T 3 \\
\text { 3. Gleason score remains } \leqslant 6 \text { and } \leqslant 2 \text { of the repeat biopsy cores are } \\
\text { invaded with prostate cancer } \\
\text { 4. PSA doubling time is favorable and remains longer than } 3 \text { years }\end{array}$ \\
\hline
\end{tabular}

Abbreviations: PRIAS, Prostate Cancer Research International: Active Surveillance; PSA, prostate-specific antigen. highly needed evidence-based guideline for AS in PC to prevent overtreatment. $^{2}$

\section{Results so far}

Currently, worldwide over 1500 patients are included in the PRIAS study. The first study interim analysis is based on the initial 500 study inclusions. These patients were included between December 2006 and July 2008 with a median follow-up time of 1.02 year (IQR (interquartile range) $0.6-1.5$ years $)^{19}$ The 2 -year active therapy-free survival rate accounted for $73 \%$. Eighty-two men changed to active therapy during follow-up; $83 \%$ (68/82) did so on protocol basis. The other $17 \%$ of the men who switched to active therapy did so because of anxiety and/or upon request. Two hundred and sixty-one repeat biopsies were available for analysis of which $34 \%$ showed no cancer, while $22 \%$ showed a Gleason score of $>6$ or $>2$ positive biopsy cores. In $53 \%(102 / 194)$ of men with favorable biopsy results, a relatively unfavorable PSA doubling time of $0-10$ years was seen. For men with an unfavorable biopsy result this percentage amounted to $62 \%$ (33/53). Seventeen percent (4/ 24) showed T3 disease after radical prostatectomy and 50\% showed a Gleason score of $>6$. This compares favorably to the results of Klotz et $a l^{23}$ Overall, the authors stated that AS is a feasible strategy in avoiding overtreatment on the short term. When applying the strict PRIAS inclusion and follow-up protocol the result is that one out of four men who start on AS switch to active therapy within 2 years after diagnosis. ${ }^{19}$

The PRIAS study is still young and further follow-up data need to be obtained and analyzed. However, the first results look promising.

Several studies show that a program of careful selection and monitoring of men who are likely to harbor clinically insignificant cancers is a rational alternative to active treatment. The value of AS alone is still under study; however, it is not yet clear how AS performs in a combined approach (i.e. which treatment can be best chosen if a men with a clinically insignificant PC presents). The Surveillance Therapy Against Radical Treatment trial is aiming at answering such a question. It is a large randomized controlled trial in which standard treatment with surgery or radiation will be compared against AS. ${ }^{28}$ The trial is currently recruiting participants.

\section{QUALITY OF LIFE ASPECTS WITH AS}

As the clinical features of AS studies look hopeful, the quality of life aspect should definitely be taken into account. Due to screening, lowrisk cancers are diagnosed that would not have been detected during the man's lifetime in the absence of screening. Men who underwent screening are confronted with having cancer. By offering AS they could feel like no treatment is offered at all and they have to face the fact that they are living with cancer. This thought, but also the fear of disease progression, can cause psychological problems.

\section{Results from the PRIAS trial}

van den Bergh et al. ${ }^{29-31}$ assessed the impact of AS on the quality of life of men participating in PRIAS. van den Bergh firstly looked at the level of knowledge of PC and the perception of AS in men on AS. ${ }^{29}$ It could be that patients perceive AS as a complex or contradictory treatment strategy, especially if these men are lower educated. Perception of the disease is an important aspect of treatment satisfaction. If men have a wrong perception of AS, treatment will most probably not be satisfactory. A hundred and fifty men who were recently diagnosed with PC received a questionnaire containing a 15 -item measure on general knowledge of PC, an open-ended question on the most important advantages and disadvantages of AS and questions on the specific 
perception of AS. It was hypothesized that younger and higher-educated men showed higher knowledge scores. van den Bergh et al. ${ }^{29}$ reported that the patients included in the cohort had an adequate knowledge of PC and realistic expectations of AS. No true misconceptions on AS were identified.

van den Bergh et al. ${ }^{30}$ initiated a study regarding the levels of anxiety and distress among men on AS who were living with 'untreated' cancer. These possible feelings of anxiety and distress were quantified in a questionnaire using the decisional conflict scale (DCS), a measure for generic anxiety (STAI-6), depression (CES-D), PC-specific anxiety (MAX-PC), physical health (SF-12 PCS), personality (EPQ) and shared decision making. A hundred and fifty men received a questionnaire, of which 129 men responded by sending the questionnaire back (response rate of $86 \%$ ). The majority of men included in this protocolbased program for AS showed favorable anxiety and distress scores in comparison with reference values and to groups of patients with PC who underwent other types of treatment. ${ }^{30}$ It turned out that some aspects, such as a poor physical health, high PSA levels and a high neuroticism score, were associated with one or more (neuroticism scores) of the CES-D, STAI-6, DCS and MAX-PC scores. A neurotic personality is therefore associated with unfavorable scores. After 9 months, the 129 men who filled in the first questionnaire received a second questionnaire. The aim was to investigate whether the levels of anxiety and distress among patients on AS changed over time. The response rate regarding the second questionnaire amounted to $90 \%$. Men with low-risk PC who started and remained on AS during 9 months, remain to have favorable levels of anxiety and distress. Only 2/129 men (2.6\%) discontinued AS because of non-medical reasons.

\section{Other results}

Whereas van den Bergh et al. ${ }^{30,31}$ reported favorable levels of anxiety and distress among men under AS, Wallace ${ }^{32}$ reported that men undergoing watchful waiting (i.e. initial surveillance followed by active treatment if and when tumour progression produces symptoms ${ }^{32}$ ) were uncertain. This uncertainty results in or from their perception of danger and therefore influences men's quality of life. Latini et $a .^{33}$ reported that treatment decisions were influenced by cancer anxiety and that more psychosocial support should be provided to men. Patel et al. ${ }^{34}$ found, in an evaluation of men undergoing AS, that $8 \%$ of men with no evidence of cancer progression were given active treatment because they had significant anxiety about the possibility of progression and about living with cancer. These results point towards the need of appropriate teaching and management interventions to alleviate anxiety.

van den Bergh et al. ${ }^{29}$ reported that men on AS had adequate knowledge of PC. Avery et al. ${ }^{35}$ reported that while most men found PSA testing and biopsy acceptable, their perception of risk were not always accurate. It should be stressed to men that the lack of relationship between the risk of PC and urinary symptoms is essential; urinary symptoms are more likely to indicate benign rather than malignant prostate disease. Next to that a two-stage information process may also be necessary to overcome barriers at both PSA testing and prostate biopsy. The provision of more tailored information on the one hand improves PC knowledge, while on the other hand it helps to facilitate informed decision making.

Furthermore, few studies regarding quality of life in men undergoing AS have been performed. Even fewer studies have measured utilities for AS health states. Utilities derived from Ref. 36 were used by Hayes et al. ${ }^{16}$ in a modeling study. They concluded that under a wide range of assumptions AS is a reasonable approach for a 65-yearold man with low-risk PC. Hayes et al. ${ }^{16}$ performed a decision analysis to assess the quality-adjusted life expectancy of AS compared with initial definitive treatment with radical prostatectomy, intensitymodulated radiation therapy or brachytherapy. The authors reported that AS was the most effective strategy, with intensity-modulated radiation therapy for progression. The most effective strategy was defined as the strategy that was associated with the highest qualityadjusted life expectancy. AS provided 6 additional months of qualityadjusted life expectancy as compared to brachytherapy, i.e. the most effective initial treatment. However, it should be taken into account that the model is based on individual patient utilities and that the decision analysis only modeled outcomes for 65-year-old men.

\section{SHARED DECISION MAKING}

In the light of the above and taking into account that PSA is still the most important pillar for diagnosing PC, it is important to enhance informed and shared decision making. ${ }^{37-39}$ According to Marteau, an informed choice can be described as 'a choice that is based on relevant knowledge, consistent with the decision maker's value and behaviorally implemented' ${ }^{40}$ Marteau $^{40}$ describes that at the beginning of the twenty-first century screening was largely viewed as a public health activity which was aimed at reducing disease prevalence. To achieve this, the emphasis has been upon high rates of uptake, and not upon an informed choice. Throughout the years, a shift in emphasis towards informed choice has occurred. ${ }^{40}$ Several considerations reflect this shift. First, it reflects an increasing recognition of the fact that it is unethical for individuals not to be informed of the consequences of medical interventions. Men undergoing a PSA test should be made aware of the consequences that the PSA test could have on their lives. It is not just the pros and cons of the PSA test that should be weighted. Second, it reflects a belief that an informed choice is associated with better patient outcomes, as compared to an uninformed choice. Finally, the concern that failure to appreciate the consequences of screening may result in litigation has also resulted in the emphasis towards an informed choice. As PC screening is available to more men nowadays, it is important to raise awareness around an informed choice. Earlier it was already described that the PSA test is currently the most commonly used screening tool for PC. ${ }^{41}$ However, the PSA test has both strengths and weaknesses. Men deciding to undergo PSA testing should be aware of both, which enables them to make a choice that is consistent with their individual values. It is also important for men to be informed about further medical consequences. If a PSA of $\geqslant 3.0 \mathrm{ng} \mathrm{ml}^{-1}$ is measured, in most cases a prostate biopsy will be recommended. ${ }^{5}$ Nijs et al. ${ }^{42}$ reported that the idea of undergoing a prostate biopsy already caused anticipated pain and discomfort. Zisman et al. ${ }^{43}$ found that undergoing a prostate biopsy can have an impact on the patient's well-being due to causing pain and anxiety. Macefield et al. ${ }^{44}$ reported that although most men coped well with undergoing a biopsy, a minority experienced elevated distress at the time of biopsy and after receiving a negative result. The authors stress that men should be informed of the risk of distress that is related to diagnostic uncertainty before consenting to PSA testing and possibly undergoing a biopsy.

While uncertainties persist around screening for PC using a PSA test, combining informed decision making with shared decision making seems a logical step. If patients are able to make an informed choice, it is certain that their choice balances their personal values. By also recommending shared decision making, the professional and the patient will share information, jointly participate in the decision 
making and agree in a course of action that incorporates the patient's personal preferences. ${ }^{45}$

In general, decision aids help men make an informed decision about a number of preventive measures and treatments. ${ }^{8}$ Throughout the years, several aids have been developed specifically to address PSA testing, ${ }^{8,46-52}$ all showing a positive effect on informed decision making. O'Connor et al. ${ }^{51}$ lists several elements which should be enhanced in a good decision aid: (i) improve knowledge of the problem, options and outcomes; (ii) create realistic expectations of outcomes; (iii) clarify personal values for outcomes; (iv) promote congruence between values and choice; (v) reduce decisional conflict; (vi) promote implementation of choices; and (vii) improve satisfaction with decision making.

In an evaluation study of decision points provided with the paper version of a risk indicator the value of informed decision making has been assessed. ${ }^{41}$ Two questionnaires were sent to a random sample of 2000 men, age 55-65 years. An informed choice in this study was defined as 'relevant knowledge about the PSA test, a positive attitude towards a PSA test, and undergoing a PSA test'. A man also makes an informed choice if he has relevant knowledge about the PSA test, has a negative attitude towards the test and does not undergo it. Other combinations reflected an uninformed choice. van Vugt et al. ${ }^{41}$ reported that significantly more men met the requirements of an informed choice after receiving information on PC and after receiving an individualized risk estimate made possible with a PC risk calculator: $81 / 535$ men $(15 \%)$ at the first versus $174 / 522(33 \%)$ at the second assessment $(P<0.001)$.

Volk et al. ${ }^{53}$ reported that decision aids, focused on PC screening, showed a long-term effect on screening behavior and also promoted informed decision making.

As shared decision making is being engaged in several major guidelines (American Urological Association, American Cancer Society and the US Preventive Services Task Force), ${ }^{45}$ the question rises whether shared decision making is applied effectively in practice. Several studies confirm that shared decision making is applied in practice; ${ }^{45,53-55}$ however, it appears that discrepancies exist between the preferred role and the actual role of patients in the decision-making process. ${ }^{56}$ Men are becoming more active in the decision-making process, as the study by Davison and Degner ${ }^{57,58}$ (32\% of men wanting their physician to make the final decision, versus $58 \%$ of men in a similar conducted study 5 years earlier) shows. However, in general it is still the doctor who sets the agenda and who decides how much information is presented to the patient. ${ }^{56}$ Whether effective shared decision making is reached is affected by the willingness of the urologist to involve the patient in the decision-making process.

\section{CONCLUSIONS}

Throughout the years, the knowledge on PSA and the PSA test has increased. However, that has not led to an unambiguous trust in the PSA test. The sensitivity and specificity of the PSA test are not optimal. Since no other prostate-specific biomarker is currently available, the PSA test will stay the most important diagnostic tool in both clinical and screening settings. Several screening studies, all using the PSA test as a diagnostic tool, have provided evidence regarding the efficacy of screening. Screening can lead to a disease-specific mortality reduction; however, it is currently also associated with overdiagnosis and overtreatment. AS seems a realistic strategy in avoiding overtreatment. AS is the subject of several ongoing studies, of which the results look promising.

It is important to enhance shared and informed decision making, because on the one hand the pros and cons of PSA testing should be clear to men who wish to be screened. On the other hand, informed and shared decision making can play a role when choosing a treatment strategy, especially when there are more options.

\section{SUGGESTIONS FOR THE FUTURE}

Since Steginga et al. ${ }^{59}$ reported that an informed choice about PSA testing was the exception rather than the rule, and since the advantages for patients have been documented by now, more urologists should enhance informed and shared decision making in clinical practice. Many men are tested without a preceding discussion or even because PSA is included in routine lists of laboratory tests. In the United States current guidelines recommend that PC screening should be discussed with patients and that a PSA test should be provided to those men who decide to be tested. ${ }^{60-62}$ However, if a man is not aware of the pros and cons of the test, as well as the consequences the result of the test can have, the doctor deciding for them does not seem justifiable, since decision making should balance personal values. A doctor can help in making such a decision; however, he should not make the decision himself unless asked.

\section{COMPETING FINANCIAL INTERESTS}

The authors declare no competing financial interests.

1 Bangma $\mathrm{CH}$. Indolent prostate cancer and active surveillance. Cancer World JanuaryFebruary 2010: 15-21.

2 van den Bergh RCN, Roemeling S, Roobol MJ, Roobol W, Schröder FH, Bangma CH. Prospective validation of active surveillance in prostate cancer: the PRIAS study. Eur Urol 2007; 52: 1560-3.

3 Flocks RH, Urich VC, Patel CA, Opitz JM. Studies on the antigenic properties of prostatic tissues. J Urol 1960; 84: 134-43.

4 Kouriefs C, Sahoyl M, Grange P, Muir G. Prostate-specific antigen through the years Arch Ital Urol Androl 2009; 81: 195-8.

5 Schröder FH, Hugosson J, Roobol MJ, Tammela TL, Ciatto S et al. Screening and prostate-cancer mortality in a randomized European study. New Engl J Med 2009; 360: 1320-8.

6 Andriole GL, Crawford ED, Grubb RL 3rd, Buys SS, Chia D et al. Mortality results from a randomized prostate-cancer screening trial. New Engl J Med 2009; 360: 1310-9.

7 Hugosson J, Carlsson S, Aus G, Bergdahl S, Khatami A et al. Mortality results from the Göteborg randomised population-based prostate-cancer screening trial. Lancet Oncol 2010; 11: 725-732.

8 Costanza ME, Luckmann RS, Rosal M, White MJ, Lapelle $\mathrm{N}$ et al. Helping men make an informed decision about prostate cancer screening: a pilot study of telephone counselling. Patient Educ Couns; e-pub ahead of print 14 January 2010; doi: 10.1016/j.pec.2010.05.011

9 Schröder FH. Review of diagnostic markers for prostate cancer. Recent Results Cancer Res 2009; 181: 173-82.

10 Thompson IM, Pauler DK, Goodman PJ, Tangen CM, Lucia MS et al. Prevalence of prostate cancer among men with a prostate-specific antigen level $<$ or $=4.0 \mathrm{ng}$ per millilitre. New Engl J Med 2004; 350: 2239-46.

11 Evans R, Edwards AG, Elwyn G, Watson E, Grol R et al. 'It's a maybe test': men's experiences of prostate-specific antigen testing in primary care. Br J Gen Pract 2007; 57: 303-10.

12 Rai T, Clements A, Bukach C, Shine B, Austoker J et al. What influences men's decision to have a prostate-specific antigen test? A qualitative study. Fam Pract 2007; 24: 365-71.

13 Ferlay JBF, Pisani P, Parkin DM. GLOBOCAN 2002. Cancer incidence, mortality and prevalence worldwide. Version 1.0. IARC Cancer Base no. 5. Lyon: IARC Press; 2004.

14 Klotz L. Active surveillance for prostate cancer: patient selection and management. Curr Oncol 72010; Suppl 2, S11-7.

15 Challacombe BJ, Murphy D, Lilja H, Vickers AJ, Costello AJ. The continuing role of prostate-specific antigen as a marker for localized prostate cancer: 'do not throw the baby out with the bath water'. BJU Int 2009; 104: 1553-4.

16 Hayes JH, Ollendorf DA, Pearson SD, Barry MJ, Kantoff PW et al. Active surveillance compared with initial treatment for men with low-risk prostate cancer: a decision analysis. JAMA 2010; 304: 2373-80.

17 D'Amico AV, Whittington R, Malkowicz SB, Fondurulia J, Chen MH et al. Pretreatment nomogram for prostate-specific antigen recurrence after radical prostatectomy or external-beam radiation therapy for clinically localized prostate cancer. J Clin Oncol 1999; 17: 168-72.

18 Draisma G, Boer R, Otto SJ, van der Cruijsen IW, Damhuis RA et al. Lead times and overdetection due to prostate-specific antigen screening: estimates from the 
European Randomized study of Screening for Prostate Cancer. J Natl Cancer Inst 2003; 95: 868-78.

19 van den Bergh RC, Vasarainen H, van der Poel HG, Vis-Maters JJ, Rietbergen JB et al. Short-term outcomes of the prospective multicenter 'Prostate Cancer Research International: Active Surveillance' study. BJU Int 2010; 105: 956-62.

20 Roemeling S, Roobol MJ, Postma R, Gosselaar C, van der Kwast TH et al. Management and survival of screen-detected prostate cancer patients who might have been suitable for active surveillance. Eur Urol 2006; 50: 475-82.

21 Parker C. Active surveillance: towards a new paradigm in the management of early prostate cancer. Lancet Oncol 2004; 5: 101-6.

22 van Vugt $\mathrm{HA}$, Bangma $\mathrm{CH}$, Roobol MJ. Should prostate-specific antigen testing be offered to asymptomatic men? Expert Rev AntiCancer Ther 2010; 10: 1043-53.

23 Klotz L, Zhang L, Lam A, Nam R, Mamedov A et al. Clinical results of long-term followup of a large, active surveillance cohort with localized prostate cancer. J Clin Oncol 2010; 28: 126-31.

24 Carter HB, Walsh PC, Landis P, Epstein IJ. Expectant management of nonpalpable prostate cancer with curative intent: preliminary results. J Urol 2002: 167: 1231-4.

25 Carter HB, Kettermann A, Warlick C, Metter EJ, Landis P et al. Expectant management of prostate cancer with curative intent: an update of the Johns Hopkins experience. $J$ Urol 2007; 178: 2359-64; discussion 2364-5.

26 Kakehi Y, Kamoto T, Shiraishi T, Ogawa O, Suzukamo Y et al. Prospective evaluation of selection criteria for active surveillance in Japanese patients with stage T1cNOMO prostate cancer. Jpn J Clin Oncol 2008; 38: 122-8.

27 Roemeling S, Roobol MJ, de Vries SH, Wolters T, Gosselaar C et al. Active surveillance for prostate cancers detected in three subsequent rounds of a screening trial: characteristics, PSA doubling times, and outcome. Eur Urol 2007; 51: 1244-51.

28 Klotz L, Kibel A, Sanda M. Observation of radical treatment in patients with prostate cancer. US National Institutes of Health, ClinicalTrials.gov: NCT00499174. 2007.

29 van den Bergh RC, van Vugt HA, Korfage IJ Steyerberg EW, Roobol MJ et al. Disease insight and treatment perception of men on active surveillance for early prostate cancer. BJU Int 2010; 105: 322-8.

30 van den Bergh RC, Essink-Bot ML, Roobol MJ, Wolters T, Schröder FH et al. Anxiety and distress during active surveillance for early prostate cancer. Cancer 2009; 115: 3868-78.

31 van den Bergh RC, Essink-Bot ML, Roobol MJ, Schröder FH, Bangma $\mathrm{CH}$ et al. Do anxiety and distress increase during active surveillance for low risk prostate cancer? J Urol 2010; 183: 1786-91.

32 Wallace M. Uncertainty and quality of life of older men who undergo watchful waiting for prostate cancer. Oncol Nurs Forum 2003; 30: 303-9.

33 Latini DM, Hart SL, Knight SJ, Cowan JE, Ross PL et al. The relationship between anxiety and time to treatment for patients with prostate cancer on surveillance. J Urol 2007; 178: 826-31.

34 Patel MI, DeConcini DT, Lopez-Corona E, Ohori M, Wheeler T et al. An analysis of men with clinically localized prostate cancer who deferred definitive therapy. J Urol 2004; 171: 1520-4

35 Avery KN, Blazeby JM, Lane JA, Neal DE, Hamdy FC et al. Decision-making about PSA testing and prostate biopsies: a qualitative study embedded in a primary care randomised trial. Eur Urol 2008; 53: 1186-93.

36 Dale W, Basu A, Elstein A, Meltzer D. Predicting utility ratings for joint health states from single health states in prostate cancer: empirical testing of 3 alternative theories. Med Decis Making 2008; 28: 102-12.

37 Korfage IJ, van den Bergh RC, Essink-Bot ML. Deciding on PSA-screening-quality of current consumer information on the internet. Eur J Cancer 2010; 46: 3073-81.

38 Allen JD, Othus MK, Hart A Jr, Mohllajee AP, Li Y et al. Do men make informed decisions about prostate cancer screening? Baseline results from the 'Take the Wheel' Trial. Med Decis Making 2010 May 18.

39 Evans R, Joseph-Williams N, Edwards A, Newcombe RG, Wright P et al. Supporting informed decision making for prostate specific antigen (PSA) testing on the web: an online randomized controlled trial. J Med Internet Res 2010; 12: e27.

40 Marteau TM, Dormandy E, Michie S. A measure of informed choice. Health Expect 2001; 4: 99-108.
41 van Vugt HA, Roobol MJ, Venderbos LD, Joosten-van Zwanenburg E, Essink-Bot ML et al. Informed decision making on PSA testing for the detection of prostate cancer: an evaluation of a leaflet with risk indicator. Eur J Cancer 2010; 46: 669-77.

42 Nijs HG, Essink-Bot ML, de Koning HJ, Kirkels WJ, Schröder FH. Why do men refuse or attend population-based screening for prostate cancer? J Public Health Med 2000; 22: 312-16.

43 Zisman A, Leibovici D, Kleinmann J, Siegel YI, Lindner A. The impact of prostate biopsy on patient well-being: a prospective study of pain, anxiety and erectile dysfunction. J Urol 2001; 165: 445-54.

44 Macefield RC, Metcalfe C, Lane JA, Donovan JL, Avery KN et al. Impact of prostate cancer testing: an evaluation of the emotional consequences of a negative biopsy result. Br J Cancer 2010; 102: 1335-40.

45 Woolf SH, Krist A. Shared decision making for prostate cancer screening: do patients or clinicians have a choice? Arch Intern Med 2009; 169: 1557-9.

46 Partin MR, Nelson D, Radosevich D, Nugent S, Flood AB et al. Randomized trial examining the effect of two prostate cancer screening educational interventions on patient knowledge, preferences and behaviors. J Gen Intern Med 2004; 19: 835-42.

47 Frosch DL, Kaplan RM, Felitti V. The evaluation of two methods to facilitate shared decision making for men considering the prostate-specific antigen test. J Gen Intern Med 2001; 16: 391-8.

48 Frosch DL, Kaplan RM, Felitti VJ. A randomized controlled trial comparing internet and video to facilitate patient education for men considering the prostate specific antigen test. J Gen Intern Med 2003; 18: 781-7.

49 Taylor KL, Davis JL 3rd, Turner RO, Johnson L, Schwartz MD et al. Educating African American men about the prostate cancer screening dilemma: a randomized intervention. Cancer Epidemiol Biomarkers Prev 2006; 15: 2179-88.

50 Myers RE, Daskalakis C, Cocroft J, Kunkel EJ, Delmoor E et al. Preparing AfricanAmerican men in community primary care practices to decide whether or not to have prostate cancer screening. J Natl Med Assoc 2005; 97: 1143-54.

51 O'Conner AM, Fiset V, DeGrasse C, Graham ID, Evans W et al. Decision aids for patients considering options affecting cancer outcomes: evidence of efficacy and policy implications. J Natl Inst Monogr 1999:7-80.

52 Gattellari M, Ward JE. Does evidence-based information about screening for prostate cancer enhance consumer decision-making? A randomised controlled trial. J Med Screen 2003; 10: 27-39.

53 Volk RJ, Spann SJ, Cass AR, Hawley ST. Patient education for informed decision making about prostate cancer screening: a randomized controlled trial with 1-year follow-up. Ann Fam Med 2003; 1: 22-8.

54 Krist AH, Woolf SH, Johnson RE, Kerns JW. Patient education on prostate cancer screening and involvement in decision making. Ann Fam Med 2007; 5: 112-9.

55 Hoffman RM, Couper MP, Zikmund-Fisher BJ, Levin CA, McNaughton-Collins M et al. Prostate cancer screening decisions: results from the National Survey of Medical Decisions (DECISIONS study). Arch Intern Med 2009; 169: 1611-8.

56 Shepherd HL, Butow PN, Tattersall MH. Factors which motivate cancer doctors to involve their patients in reaching treatment decisions. Patient Educ Couns 2010 Nov 25.

57 Davison BJ, Degner LF. Empowerment of men newly diagnosed with prostate cancer. Cancer Nurs 1997; 20: 197-96.

58 Davison BJ, Degner LF, Morgan TR. Information and decision-making preferences of men with prostate cancer. Oncol Nurs Forum 1995; 22: 1401-8.

59 Steginga SK, Pinnock C, Jackson C, Gianduzzo T. Shared decision-making and informed choice for the early detection of prostate cancer in primary care. BJU Int 2005; 96: 1209-10.

60 Lim LS, Sherin K, Committee APP. Screening for prostate cancer in U.S. men ACPM position statement on preventive practive. Am J Prev Med 2008; 34: 164-70.

61 Force USPST. Screening for prostate cancer: U.S. Preventive Services Task Force recommendation statement. Ann Intern Med 2008; 149: 185-91.

62 Wolf AM, Wender RC, Etzioni RB, Thompson IM, D'Amico AV et al. American Cancer Society guideline for the early detection of prostate cancer: update 2010. CA Cancer J Clin 2010; 60: 70-98. 